\title{
Percepção de agricultores familiares e empresariais de Tomé-Açu, Pará, Brasil sobre os Sistemas de Agrofloresta
}

\section{Smallholder families and commercial farmers' perception on Agroforestry Systems in Tomé-Açu, Pará, Brazil}

Gisele do Socorro dos Santos Pompeu ${ }^{\mathrm{a}}$

Osvaldo Ryohei Kato ${ }^{b}$

Ruth Helena Cristo Almeidac

aProfessora da Faculdade de Educação do Campo, Universidade Federal do Pará, Campus Cametá, Cametá, PA, Brasil. End. Eletrônico: giflorestal@yahoo.com.br

${ }^{b}$ Pesquisador da Empresa Brasileira de Pesquisa Agropecuária - Embrapa Amazônia Oriental, Belém, PA, Brasil. End.Eletrônico: osvaldokato@gmail.com

'Professora da Universidade Federal Rural da Amazônia, Belém, PA, Brasil. End. Eletrônico: ruth.almeida@ufra.edu.br

doi:10.18472/SustDeb.v8n3.2017.24197

\section{Recebido em 30.01.2017}

Aceito em 04.10.2017

ARTIGO - VARIA

\section{RESUMO}

Neste artigo avalia-se a percepção agroflorestal dos agricultores da agricultura familiar e empresarial do município de Tomé-Açu, estado do Pará. A percepção dos agricultores foi importante para construir relações com a natureza durante a implantação e manejo dos sistemas agroflorestais (SAF), no entanto, reconhecemos que essa percepção precisa ser mais bem investigada. Para o desenvolvimento da pesquisa, foram realizadas abordagens quantitativa e qualitativa, aplicadas entrevistas com roteiro semiestruturado, realizadas caminhadas transversais com observação direta e anotações em um diário de campo. Analisaram-se os dados pela estatística descritiva no programa SPSS 19.0. As percepções dos agricultores sobre os SAF são distintas. O caráter ambiental é considerado pelos agricultores familiares, devido sua visão histórico-cultural de manejo dos sistemas e por identificarem a necessidade de sombreamento e valorização dos serviços ecossistêmicos. Já os agricultores empresariais baseiam-se em observações econômicas. Diante das análises, ressaltamos que o apoio da Cooperativa Agrícola Mista de Tomé-Açu (Camta), Associação dos Produtores e Produtoras Rurais da Agricultura Familiar do Município de Tomé-Açu (Apprafamta) e instituições de ensino e pesquisa é importante na difusão da informação e intercâmbio de experiências para a transição agroecológica.

Palavras-chave: Amazônia; Agrofloresta; Sustentabilidade; Uso da Terra. 


\section{ABSTRACT}

This article evaluates the agroforestry perception of smallholders and agrobusiness farmers in the town of Tomé-Açu, State of Pará. The perception of farmers was important to build relationships with nature during the implementation and management of agroforestry systems (AFS), however, more work needs to be done in order to better understand this perception. For this purpose, quantitative and qualitative approaches were applied, interviews with semi-structured scripts were carried out, crosscut walks in rural areas with direct observation and annotations were done in a field diary. Data were analyzed by descriptive statistics in the SPSS 19.0 program. The farmers' perceptions about AFS are distinct. The environmental feature is considered by smallholders due to their historical-cultural view of systems management and the necessity for shadowing and valorization of ecosystem services. The commercial concerns are more relevant to agrobusiness farmers It is worth noting that, in view of the analysis, the support of CAMTA (Mixed Agricultural Cooperative of Tomé-Açu), APPRAFAMTA (Association of Rural Producers and Producers of Family Agriculture of Tomé-Açu) and educational and research institutions is important in the dissemination of information and the exchange of experiences for the agroecological transition.

Keywords: Amazon; Agroforestry; Sustainability; Land Use

\section{INTRODUÇÃO}

Os sistemas agroflorestais (SAF) têm sido apresentados como uma manifestação concreta de estilo de agricultura com maior nível de sustentabilidade econômica, ambiental e sociocultural. Tornam-se uma alternativa eficaz para a produção sustentável de alimentos e serviços ambientais (PORRO, 2009; PALUDO; COSTABEBER, 2012; PEZARICO et al., 2013).

Apesar das vantagens proporcionadas, há necessidade de analisar os SAF a partir do enfoque sistêmico. Tal necessidade surge diante da crescente complexidade dos sistemas manejados e da emergência do conceito de sustentabilidade que lançou novos desafios no rural, especialmente sobre a questão socioambiental. Pinheiro (2000) afirma que os sistemas agropecuários têm requerido uma abordagem holística e multidisciplinar, a fim de melhor serem analisados e compreendidos.

Nessa perspectiva, os estudos sobre percepção no espaço agroflorestal buscam analisar a experiência cotidiana do agricultor e o contato com a natureza, buscando compreender a complexidade do mundo vivenciado em uma perspectiva que transcenda os valores técnicos e funcionalistas. As abordagens, geralmente, desconsideram a experiência de vida dos agricultores, deixam de vislumbrar a produção do conhecimento significativo sobre suas variadas práticas cotidianas, bem como as percepções do espaço e do lugar produzido e vivido (FRAXE, 2006).

A percepção dos agricultores sobre sistemas diversificados de produção agrícola apresenta distinção em função do modo de vida e grupo social aos quais estão inseridos. Portanto, é necessário conhecer as características dos produtores para compreender quais os pontos comuns e as diferenças enquanto atores socioeconômicos e produtores do espaço (LEFÈBVRE, 2003) de modo a contribuir para o desenvolvimento das atividades produtivas locais.

Estudos conduzidos por Goulart (2016) em Mato Grosso abordaram questões sobre as percepções dos agricultores em relação aos pontos positivos e limitações das agroflorestas, além de questões relativas aos aprendizados a partir dos plantios agroflorestais. Foi constatado que a adoção das práticas de manejo relacionou-se, especialmente, às questões ligadas aos valores e experiências repassadas pelos antepassados dos agricultores.

Barros et al. (2009) apontam que os SAF de Tomé-Açu, estado do Pará, podem sofrer mudanças ao longo do tempo, decorrentes das condições de preços, do mercado, do aparecimento de pragas e doenças, de mudanças nas políticas públicas beneficiando determinadas culturas, legislação trabalhista ou ambiental, envelhecimento do proprietário, entre outras. 
Tais mudanças nem sempre ocorrem na mesma velocidade entre os agricultores familiares e empresariais, devido, provavelmente, às distintas percepções desses agricultores em relação aos SAF. Questões relacionadas a tradições familiares, à origem geográfica e ao nível de escolaridade são apontadas por Raiol e Rosa (2013), Vieira et al. (2013) e Ferreira et al. (2014) como possíveis fatores relacionados a distintas percepções que influenciam o manejo dos sistemas.

Desse modo, por meio do estudo sobre percepção, é possível compreender as mudanças ocorridas nos SAF de Tomé-Açu, e as implicações para a sustentabilidade. A pesquisa poderá contribuir, portanto, para a compreensão de pesquisadores e extensionistas sobre as diferentes estratégias utilizadas pelos agricultores no manejo dos sistemas, em função da percepção apreendida; e, assim, aperfeiçoar procedimentos de abordagem junto aos agricultores agroflorestais.

O objetivo desta pesquisa foi avaliar a percepção agroflorestal dos agricultores da agricultura familiar e empresarial do município de Tomé-Açu, estado do Pará.

\section{FUNDAMENTAÇÃO TEÓRICA}

\subsection{A PERCEPÇÃO NO CONTEXTO AMBIENTAL}

Estudos sobre percepção no campo ambiental são iniciativas relativamente novas se comparadas à inserção da temática em outros campos de conhecimento, como a psicologia e a geografia (MARIN, 2008). O termo "percepção" inclui, além das percepções bio-fisiológicas, as imagens que são formadas mentalmente sobre o mundo vivido, as memórias, experiências, predileções, interpretações, atitudes e expectativas (DEL RIO, 1999).

Os laços que unem o ser humano à natureza são construídos não só dos conceitos que o ser humano tem sobre o meio ambiente, mas de outros aspectos inerentes à sua natureza, desde os mais rudimentares (instintivos) até os associados à sua complexa evolução biológica e cultural (MARIN et al., 2008).

Sob o ponto de vista ambiental busca-se, por meio do estudo sobre a percepção, compreender a complexidade vivenciada em uma perspectiva que vai além dos valores técnicos que, por vezes, desconsideram a experiência de vida e o conhecimento das práticas diárias, bem como as percepções do espaço e do lugar produzido/vivido (MARIN, 2008).

A relação intrínseca homem-natureza, sempre mediada pelo trabalho e da qual o homem é sujeito integrante, é a responsável pela geração da percepção espacial do homem em razão da sua vida no e com o ambiente, sendo o resultado desse processo as representações sociais (FRAXE et al., 2006).

Uma das dificuldades para a proteção dos ambientes naturais está na existência de diferenças nas percepções dos valores e da importância daqueles entre os indivíduos de culturas diferentes ou de grupos socioeconômicos que desempenham funções distintas, no plano social, nesses ambientes (VILAR et al., 2008).

As relações construídas na implantação e manejo dos SAF estão relacionadas à percepção apreendida pelo agricultor, sob uma perspectiva não somente relacionada ao caráter técnico da produção, mas também sob forte perspectiva ambiental.

Assim, o estudo sobre a percepção ambiental pode proporcionar um melhor entendimento sobre a relação estabelecida entre o homem e o ambiente, considerando os valores culturais, as expectativas, satisfações e insatisfações dos agricultores agroflorestais.

\subsection{OS SISTEMAS AGROFLORESTAIS}

Os SAF são formas alternativas de uso da terra, em que espécies arbóreas lenhosas e palmeiras são plantadas associadas às espécies agrícolas (perenes ou anuais) e/ou animais, em uma mesma área simultaneamente ou sequencial, com interações ecológicas e econômicas (NAIR, 1984; DUBOIS; VIANA, 1998; FARREL; ALTIERI, 2012). 
Existe uma variedade de combinações e possibilidades sob a designação "Sistemas Agroflorestais", que diferem quanto aos seus arranjos estruturais (espacial e temporal), fisionomia, composição florística, papel fun-cional dos componentes e aspectos ecológicos, manejo do sistema, objetivos da produção e características socioeconômicas predominantes (UMRANI; JAIN, 2010).

Na classificação de uso mais difundida, consideram-se os aspectos funcionais e estruturais como base para agrupar os SAF em categorias: Sistemas silviagrícolas - caracterizados pela combinação de árvores, arbustos ou palmeiras com espécies agrícolas; Sistemas silvipastoris - caracterizados pela combinação de árvores, arbustos ou palmeiras com plantas forrageiras herbáceas e animais. Sistemas agrossilvipastoris - caracterizados pela criação e manejo de animais em consórcios silviagrícolas (MAY, 2008).

Os povos tradicionais da Amazônia possuem vasto conhecimento sobre o manejo dos SAF e desenvolveram técnicas produtivas que continuam garantindo o equilíbrio e a manutenção dos recursos naturais (CASTRO et al., 2009).

Entre os benefícios dos SAF estão os de bem-estar e saúde pública (sombra, umidade do ar e diminuição da temperatura), proteção dos solos e dos mananciais, além dos benefícios sociais: turismo e educação ambiental (ABDO et al., 2008). Esses sistemas, além de otimizarem a área, promovem o uso múltiplo da terra (RIBASKI; MONTOYA; RODIGHERI, 2001) que, aliado aos vários estratos da vegetação, contribui para o aumento da produção, da renda e dos serviços ambientais.

Os sistemas implantados em Tomé-Açu se destacam dos demais SAF praticados pelos produtores da região, por serem desenvolvidos com tecnologias e processos que conferem maior grau de proteção ambiental e rentabilidade. São semelhantes às "ilhas de eficiência", visto que produzem conhecimento, tecnologia e processos passíveis de serem reproduzidos podendo sofrer adaptações ao longo do tempo em função do contexto socioeconômico e ambiental em que foram implantados (ARCE; LONG, 2000).

Assim, considerar práticas agrícolas adquiridas e o conjunto de estratégias empregadas na propriedade (DUBOIS; VIANA, 1998) é fundamental para compreender, entre outros, a percepção do agricultor em relação ao SAF e o conceito de viabilidade do sistema sob a óptica do agricultor, visto que, de acordo com Fernandes (2008), ao mesmo tempo em que faz parte do sistema, o homem-agricultor também é praticante de mudanças para melhorá-lo e lança mão de estratégias que modificam profundamente os sistemas e suas características ambientais e socioeconômicas.

\subsection{AGRICULTURA FAMILIAR E AGRICULTURA EMPRESARIAL}

A ocupação do meio rural brasileiro se fez de forma bastante heterogênea, porém, marcada por uma estrutura fundiária altamente concentrada, o que historicamente vem sendo motivo de muitos conflitos agrários. Desse modo, as ciências sociais construíram categorias de análise que permitem compreender grande parte dos atores relacionados com o setor agrícola e, dessa forma, têm feito avançar o conhecimento dos grupos sociais presentes no campo (BÜHLER, 2012).

Foram desenvolvidas abordagens voltadas à pequena propriedade, à qual se associam os estudos sobre o campesinato ou o agricultor familiar, e à grande propriedade à qual se associam os estudos sobre as plantations, as fazendas de pecuárias ou, mais recentemente, sobre o agronegócio (BÜHLER, 2012).

Para os efeitos da Lei no 11.326, de 24 de julho de 2006, em seu art. 3o (BRASIL, 2009) considerase agricultor familiar aquele que pratica atividades no meio rural, atendendo, simultaneamente, aos requisitos de não deter área maior do que 04 (quatro) módulos fiscais; utilizar predominantemente mão de obra familiar nas atividades do seu estabelecimento; possuir percentual mínimo da renda familiar originada de atividades econômicas do seu estabelecimento; e dirigir seu estabelecimento com sua família.

Na sociedade brasileira, há um discurso que estabelece uma suposta incompatibilidade entre o agronegócio e a agricultura familiar. As origens desse fato são múltiplas e por vezes político-ideológicas. 
No setor empresarial a ideia é de que as funções econômicas da agropecuária são cumpridas por unidades produtivas de grande escala que utilizam força de trabalho assalariada; em contrapartida, são imputados à agricultura familiar papéis de ordem meramente social, de gerar emprego e renda a produtores excluídos das cadeias de produção (CAUME, 2009).

No que tange às pesquisas relacionadas a esses dois grupos no rural, é notório que o número de estudos que permeiam o universo da agricultura familiar é superior ao dos estudos relativos à agricultura empresarial. Não existem muitas pesquisas acumuladas que tenham se dedicado à sua compreensão desde o campo epistemológico da geografia humana e da sociologia, e a compreensão sob a perspectiva ambiental (BÜHLER, 2012).

Por outro lado, a agricultura familiar se depara com outras dificuldades, especialmente em relação à escassez de terra, à falta de assistência técnica, à baixa disponibilidade de recursos financeiros, entre outras, que limitam seu desenvolvimento. Uma das consequências dessas limitações é a relativa dificuldade desse segmento em alcançar o padrão tecnológico vigente, necessário ao alcance de maior competitividade (SOUZA et al., 2011).

Desse modo, é necessário conhecer melhor as características dos produtores agrícolas para compreender quais os pontos comuns e quais as diferenças entre eles enquanto atores socioeconômicos e produtores do espaço (LEFÈBVRE, 2000), de modo a contribuir para o desenvolvimento das atividades produtivas locais.

\section{METODOLOGIA}

\subsection{CARACTERIZAÇÃO DO LOCAL}

O município de Tomé-Açu está situado na mesorregião do nordeste do estado do Pará. Possui área territorial de 5.145,338 $\mathrm{km}^{2}$ e população de 60.456 habitantes (IBGE, 2016). Suas coordenadas

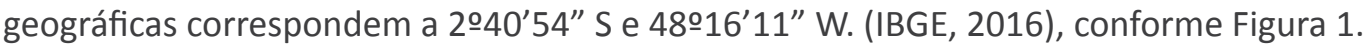

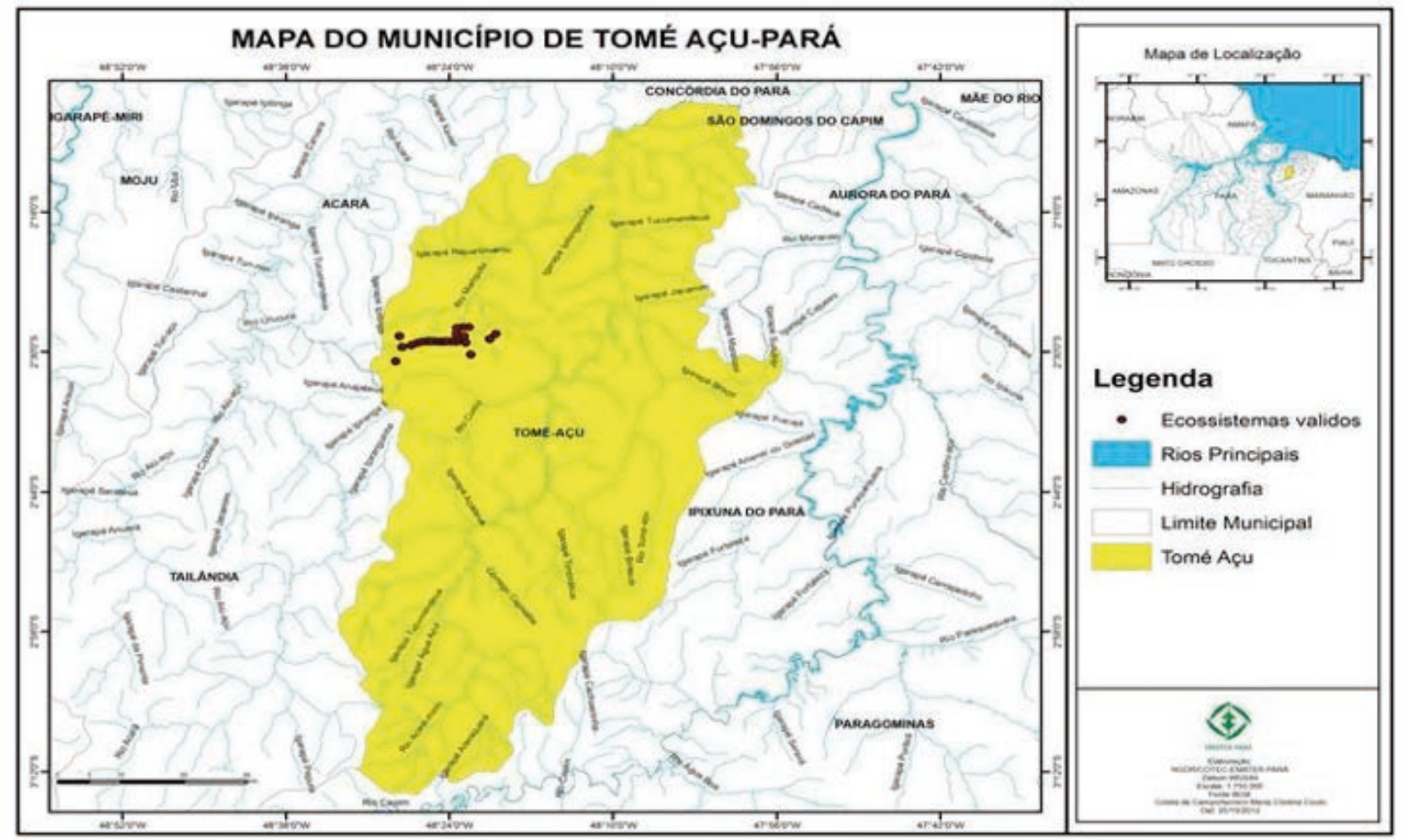

Figura 1 - Mapa do município de Tomé-Açu. 
Os solos de Tomé-Açu são representados por latossolo amarelo distrófico considerados de muito baixa fertilidade e condicionados por baixa reserva de nutrientes essenciais às culturas agrícolas (PACHÊCO; BASTOS, 2008).

O clima é mesotérmico e úmido, do tipo Ami, de acordo com a classificação de Köppen, temperatura anual de $26 \% \mathrm{C}$ e umidade relativa do ar de $85 \%$. A vegetação original é composta por floresta ombrófila densa, que encontra-se alterada, com alguma ocorrência de florestas secundárias (PACHÊCO; BASTOS, 2008).

\subsection{COLETA DOS DADOS}

O estudo foi baseado em uma pesquisa de abordagens quantitativa e qualitativa desenvolvida com agricultores de dois grupos distintos:

- Agricultura familiar (SAF-AF): agricultores vinculados à Associação de Produtores e Produtoras da Agricultura Familiar do Município de Tomé-Açu (Apprafamta);

- Agricultura empresarial (SAF-AE): agricultores vinculados à Cooperativa Agrícola Mista de Tomé-Açu (Camta).

A opção pelo estudo de caso em Tomé-Açu (PA) ocorreu devido aos SAF deste município ser diferenciados no contexto da produção agropecuária da Amazônia, considerando-se sua estrutura, potencialidades de produção diversificada (BOLFE; BATISTELLA, 2011), além dos diferentes "sujeitos" que o manejam (imigrantes japoneses, nordestinos e nortistas) que compõem os grupos em estudo.

Os agricultores da Camta têm como característica de produção a utilização de tecnologia, contratação de mão de obra, aquisição de insumos, plantio irrigado e, por fim, visam o lucro da produção, portanto, foram caracterizados como agricultores empresariais, e os agricultores da Apprafamta (conforme descrito anteriormente: Lei no 11.326, de 24 de julho de 2006) como agricultores familiares.

Optou-se pela pesquisa qualitativa devido abordar de modo eficiente o mundo real, que não pode ser quantificado, tentando descrever "de dentro" práticas cotidianas, interações e experiências, compreensão e explicação da dinâmica das relações sociais (FLICK, 2009; GERHARDT; SILVEIRA, 2009).

Em complementação utilizou-se a pesquisa quantitativa por caracterizar-se pelo emprego da quantificação na coleta de informações, e tratamento por meio de técnicas estatísticas (RICHARDSON, 1989).

A coleta de dados ocorreu em maio de 2016 por meio de entrevistas auxiliadas por um roteiro semiestruturado (BARROS et al., 2009; POMPEU et al., 2012), caminhadas transversais (ALENCAR; GOMES, 2001) com observação direta e anotações em um diário de campo.

O roteiro das entrevistas abordou os seguintes itens: a) Infor-mações gerais sobre a propriedade; b) Caracterização da unidade produtiva; c) Caracterização do sistema agroflorestal; d) Percepção sobre os sistemas; e) Vantagens/desvantagens dos sistemas; f) Perspectivas em relação aos sistemas.

Às entrevistas foi anexado um termo de consentimento no qual o entrevistado foi informado sobre a identificação do pesquisador e o objetivo da pesquisa. Os agricultores foram convidados a participar da pesquisa, e deixados à vontade para aceitar ou recusar a participação.

Obtiveram-se os tamanhos das áreas (ha) dos SAF-AF e SAF-AE, fornecidos pela Apprafamta e Camta. Devido à população dos SAF-AF ser representada por apenas 20 agricultores, optou-se por trabalhar com todos, entretanto, 05 agricultores apresentavam sistemas com desenvolvimento inicial e foram desconsiderados na amostra.

Nos SAF-AE observou-se grande variação no tamanho das áreas dos 137 agricultores, apresentando diferenças significativas entre os subgrupos. Portanto, fez-se separação das propriedades em classe de intervalos de 100 ha com o último intervalo agregando áreas superiores a 251,50 ha, mas até 350 ha para evitar grande variação nesse intervalo (Tabela 1). 


\begin{tabular}{|c|c|c|c|c|c|}
\hline Classe (ha) & $\begin{array}{c}\mathbf{N i} \\
\text { SAF }\end{array}$ & Média & $\begin{array}{l}\text { Desvio } \\
\text { padrão }\end{array}$ & Peso & $\begin{array}{c}\mathrm{Ni} \\
\text { Amostra }\end{array}$ \\
\hline $1,5-101,5$ & 117 & 48,6 & 15,41 & 0,78 & 22 \\
\hline $101,5-201,5$ & 17 & 185,38 & 14,48 & 0,15 & 03 \\
\hline$>251,5$ (até 350$)$ & 3 & 313,33 & 47,26 & 0,07 & 2 \\
\hline Total & 137 & & & 1,00 & 27 \\
\hline
\end{tabular}

Escolheu-se trabalhar com 27 agricultores (20\% da população) do universo de 137 cooperados da agricultura empresarial. Optou-se fazer uma amostragem estratificada proporcional. A divisão em subgrupos, a princípio, não está relacionada às percepções dos agricultores, mas realizada para garantir que os subgrupos (estratos) tivessem representação na amostra proporcional ao seu peso na população, de modo a não selecionar o tamanho amostral (por subgrupos) de maneira aleatória e, assim, evitar mascarar os resultados.

\subsection{ANÁLISE DOS DADOS}

Os dados foram armazenados no programa Statistical Package for the Social Sciences (SPSS 19.0 ${ }^{\circledR}$ ) e analisados pela estatística descritiva. Consideraram-se as respostas sobressalentes (frases e expressões de efeito) que compuseram os resultados sobre a percepção dos agricultores ante as questões investigadas.

As categorias de análise para avaliação da percepção ambiental foram definidas a partir das informações obtidas.

\section{RESULTADOS E DISCUSSÃO}

\subsection{POR QUE MUDAR O SISTEMA PRODUTIVO PARA O SISTEMA AGROFLORESTAL?}

O universo agroflorestal no qual os agricultores estão inseridos despertou percepções ambientais distintas que caracterizam os grupos sociais apresentados neste estudo, ratificando que a análise do campo no qual o fenômeno perceptivo se manifesta é um dos principais elementos para sua compreensão.

Quando indagados acerca do seu entendimento em relação aos SAF, os agricultores demonstraram conhecimento sobre o tema e enfatizaram a mistura de espécies e os benefícios ambientais e econômicos como características principais dos sistemas.

Vale ressaltar que na Amazônia os SAF têm origem nas experiências de comunidades indígenas no decurso de várias gerações no manejo da floresta tropical (EMBRAPA, 1991). No entanto, os modelos de SAF desenvolvidos pelos agricultores de Tomé-Açu foram os que mais se destacaram, devido às experimentações realizadas pelos agricultores e as distintas formas de manejo empregadas.

O nível atual de diversificação de espécies foi alcançado aliando o conhecimento técnico ao espírito experimentador e empreendedor dos agricultores (KATO; TAKAMATSU, 2005; HOMMA, 2007; YAMADA, 2009; BARROS et al., 2009; BOLFE; BATISTELLA, 2011). Portanto, o fato de as experiências com SAF não ser uma prática recente para os agricultores de Tomé-Açu, proporciona a eles um profundo conhecimento sobre o tema, sem necessariamente utilizar o conceito elaborado nos meios acadêmicos. 
Entre os agricultores familiares verificou-se que nem sempre o SAF é compreendido sob a óptica da comercialização. Considera-se, em grande medida, o caráter ambiental, porém, esse fator não é determinante para o entendimento apreendido pelos agricultores. Segundo Barros et al. (2009), para os agricultores empresariais, a percepção agroflorestal ocorre mais sob a óptica mercadológica.

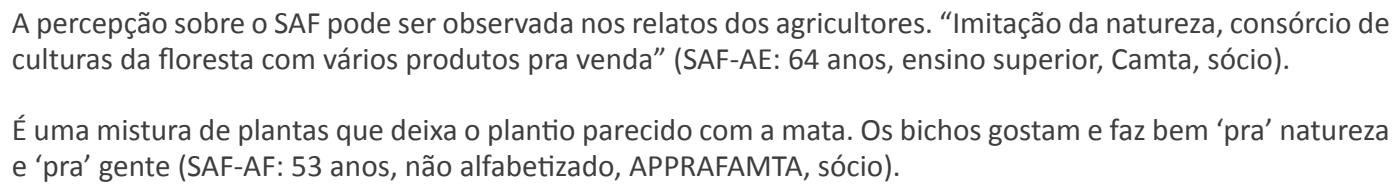

O empoderamento dos agricultores de Tomé-Açu sobre o conceito de SAF é auxiliado pela difusão da informação realizada por instituições parceiras: Empresa Brasileira de Pesquisa Agropecuária (Embrapa Amazônia Oriental), Universidade Federal Rural da Amazônia (UFRA), Universidade Federal do Pará (UFPA), Instituto Federal do Pará (IFPA), Empresa de Assistência Técnica e Extensão Rural do Pará (Emater-PA) e Comissão Executiva do Plano da Lavoura Cacaueira (Ceplac).

Em se tratando dos agricultores empresariais, ressalta-se, ainda, a ativa participação da Camta que desenvolve ações voltadas à produção sustentável, considerando os conhecimentos, as práticas agrícolas e as experimentações dos agricultores. No que diz respeito aos agricultores familiares, é válido destacar o trabalho desenvolvido pela Apprafamta, especialmente no sentido de reforçar aos agricultores a importância dos SAF como sistema produtivo sustentável.

Segundo Tafner Jr. (2014), os SAF de Tomé-Açu contribuíram para formar o alicerce responsável pela evolução da Camta e por manter as relações sociais e culturais entre os cooperados. Tais experiências são compartilhadas pelos agricultores da cooperativa com outros agricultores do município.

A investigação sobre os objetivos para a implantação dos SAF demonstrou que para $80 \%$ dos agricultores familiares e $73 \%$ dos agricultores empresariais o motivo mais importante para a implantação dos sistemas foi a geração de renda, seguida da intenção de recompor áreas desmatadas, 67\% e 20\% respectivamente (Figura 2).

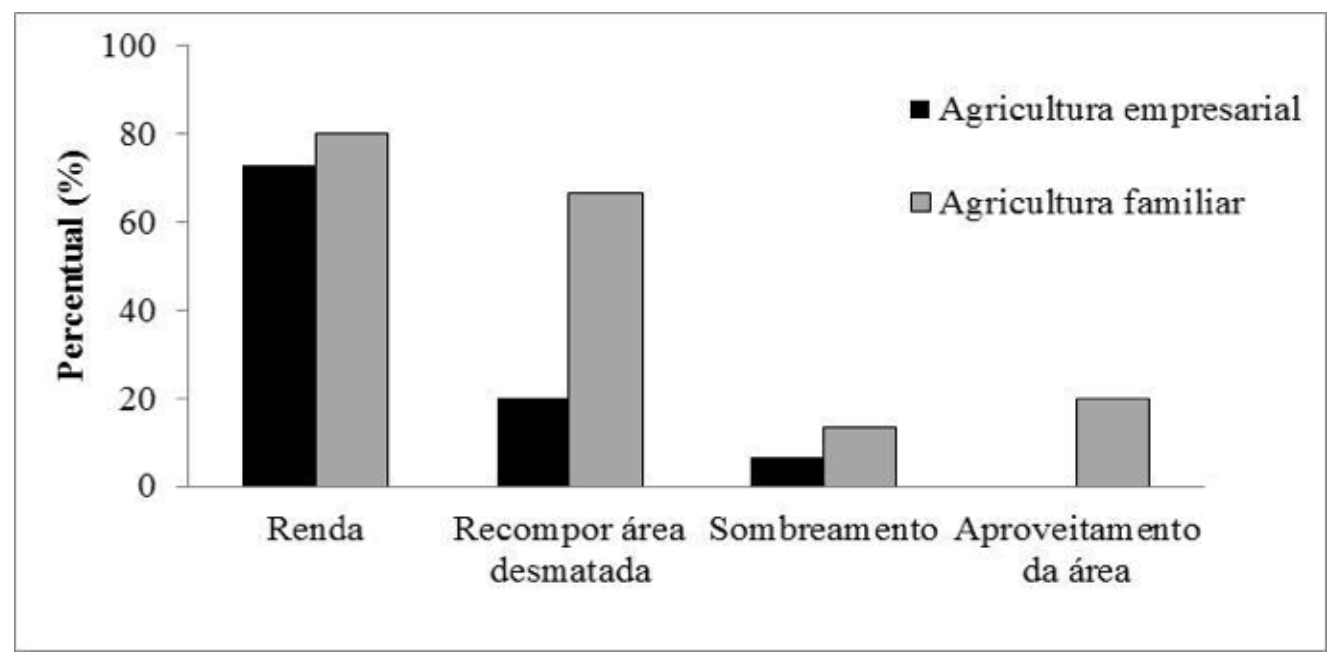

Figura 2 - Objetivo para a implantação dos sistemas agroflorestais.

Fonte: Elaboração própria.

Portanto, para os agricultores, de modo geral, a percepção de viabilidade dos SAF está associada à ideia de sustentabilidade econômica e ambiental. Logo, entende-se a razão de todos os agricultores (SAF-AF e SAF-AE) afirmarem que os SAF são melhores para trabalhar quando comparados ao monocultivo. 


\subsection{PERCEPÇÃO SOBRE UMA AGRICULTURA SUSTENTÁVEL}

\subsubsection{DIFICULDADES NO MANEJO AGROECOLÓGICO VERSUS MANEJO DOS MONOCULTIVOS}

Entre os agricultores familiares, $60 \%$ responderam que as espécies arbóreas foram plantadas e as demais selecionadas durante o preparo de área, enquanto que no grupo empresarial somente $14 \%$ dos agricultores realizaram a seleção das espécies. Esses resultados revelam que os agricultores familiares possuem maior interesse no manejo da regeneração natural para compor os sistemas.

Na percepção dos agricultores de ambos os grupos, as árvores não atrapalham o componente agrícola e foram plantadas devido à necessidade de sombreamento definitivo demandado por algumas espécies frutiferas, especialmente o cupuaçu (Theobroma grandiflorum (Willd. ex. Spreng) K. Schum) e o cacau (Theobroma cacao L.).

Quando indagados sobre como aprenderam manejar os SAF, na percepção dos agricultores empresariais a orientação técnica fornecida pela Camta teve papel importante na troca de informações, porém, as experiências compartilhadas entre os produtores foram o que mais contribuiu para a aquisição dos conhecimentos. Os agricultores familiares afirmaram que os aspectos mais importantes para o manejo foram as experiências com outros produtores e observações na propriedade.

O intercâmbio de experiências permite que haja a troca de saberes e disseminação das informações entre os agricultores, e, segundo Gliessman et al., (2007), favorece a transição para uma agricultura mais sustentável. Nesse sentido, Abdo et al. (2008) afirmam que o sucesso dos sistemas depende muitas vezes do agricultor que, amparado tecnicamente, deve ter o espírito investigativo para experimentar novas associações de culturas, sendo atento e cauteloso na observação dos resultados e problemas.

A percepção sobre a produção sustentável dos SAF ficou ainda mais evidente quando os agricultores foram instigados a compará-los ao monocultivo. Todos os agricultores familiares responderam que o melhor sistema para trabalhar são os SAF, enquanto que 03 (três) agricultores empresariais, mesmo concordando, acrescentaram que, apesar das vantagens, os SAF são muito trabalhosos sob o ponto de vista do manejo das espécies.

O relato abaixo esclarece que a lógica de plantio é a de não esperar o final do ciclo produtivo de uma espécie para iniciar o plantio de outra, o que denota o interesse na máxima diversificação e interação entre os componentes:

Eu planto primeiro a pimenta-do-reino, e aí já vou plantando o cacau, quando o pimental desaparecer, a área já ficou sombreada com o paricá que eu plantei lá no início, e o cacau já tá produzindo. O negócio é não perder tempo. Antes a gente formava o pimental e quando ele não produzia mais só restava a capoeira. Hoje em dia é diferente, a gente já planta o pimental e junto vai plantando outras coisas (SAF-AF: 55 anos, ensino fundamental, APPRAFAMTA, presidente).

Por outro lado, relato do agricultor seguinte destaca as dificuldades no manejo de várias espécies em uma mesma área, porém, ressalta a importância da diversificação na produção agroflorestal:

O SAF é bom porque tem vários produtos, mas dá muito trabalho lidar com várias plantas. No início, trabalhar com várias espécies foi um pouco complicado, mas depois de alguns anos o sistema estabiliza e é só colher os produtos, cada um na sua época. Mas, só um tipo de cultura é menos trabalhoso (SAF-AE: 42 anos, ensino fundamental, CAMTA sócio).

Os sistemas maiores (>251,5ha), localizados na agricultura empresarial, eventualmente podem apresentar mais dificuldade de manejo, entretanto, esse aspecto não é determinante, visto que SAF menores $(<101,5$ ha) apresentaram-se mais diversificados, portanto, com maior demanda nas atividades de manejo.

Apesar dos relatos sobre as dificuldades no manejo das espécies, especialmente no início dos sistemas, nenhum agricultor (familiar e empresarial) demonstrou intenção de abrir mão da atividade agroflorestal em prol de monocultivos, fato que demonstra a consolidação dos SAF como sistema produtivo no município de Tomé-Açu. 


\subsubsection{VISÃO HISTÓRICO-CULTURAL DO AMBIENTE}

Em se tratando das árvores, os agricultores familiares expressaram percepção muito particular (doméstica e familiar) considerando-as componentes fixos dos sistemas, os quais pretendem deixar para as futuras gerações. Esse resultado indica que para os agricultores familiares a valorização do componente arbóreo extrapola a perspectiva econômica, e considera também o meio ambiente, o contexto histórico e sociocultural em que as árvores foram plantadas e manejadas.

Na percepção do agricultor familiar a seguir, o plantio das castanheiras do Pará é o marco inicial dos SAF em sua propriedade, logo, representa muito mais do que um componente do sistema, "é como se fosse um membro da família":

Esta castanheira foi a primeira árvore que eu plantei no meio do pimental. Prefiro deixar as árvores de pé porque se eu derrubar "pra" vender, o meu cacau e o cupuaçu vão ficar sem sombra. O dinheiro da venda da árvore vai acabar e eu não vou ter cacau e cupu "pra" vender. Depois, as "bichinhas" são tão bonitas né, dá dó derrubar (SAF-AF: 55 anos, ensino fundamental, APPRAFAMTA, presidente).

Sobre tal relação homem-natureza, Fraxe (2006) reforça que o homem muitas vezes transcende a si mesmo e promove articulações entre as suas intenções e o mundo existente, tendo a natureza como suporte da vida, produzindo como resultado a interação homem/natureza.

\subsubsection{SOMBREAMENTO DOS CULTIVOS E PERSPECTIVA DE EXPLORAÇÃO MADEIREIRA}

A maioria dos sistemas encontra-se com nível de sombreamento entre $30 \%$ a $45 \%$, que, de acordo com Gonzáles (2006), é classificado como sombreamento mediano. Porém, os SAF mais sombreados estão presentes na agricultura familiar (Figura 3).

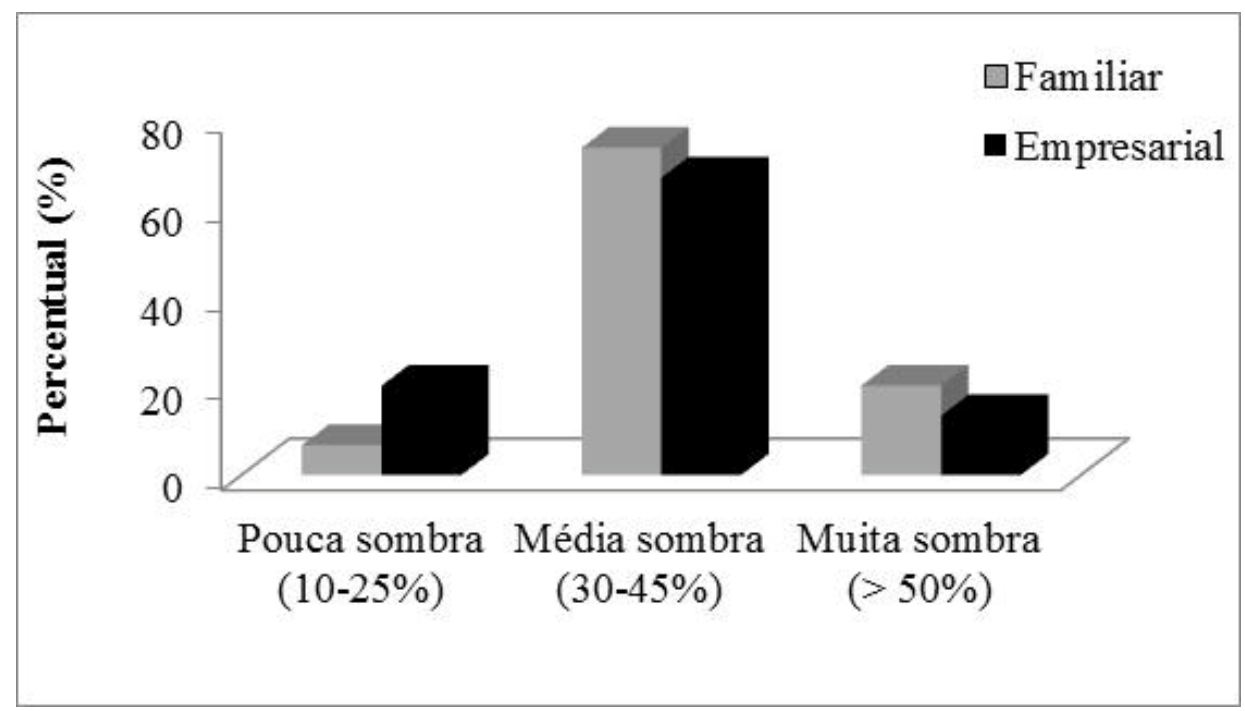

Figura 3 - Nível de sombreamento nos sistemas agroflorestais de Tomé-Açu, Pará

Fonte: Elaboração própria.

Somente um agricultor familiar pretende aumentar o sombreamento de $10 \%$ a $25 \%$ para $30 \%$ a $45 \%$, enquanto que oito agricultores empresariais desejam diminuir o sombreamento de $30 \%$ a $45 \%$ para $10 \%$ a $25 \%$.

O principal motivo para a diminuição do sombreamento é minimizar a competição entre as plantas e aumentar a produção de algumas espécies, principalmente o açaí (Euterpe oleracea Mart.) cujo mercado está em plena expansão. Essa diminuição, entretanto, interfere diretamente na produção das espécies sombreadas (cacau e cupuaçu), consideradas as principais espécies frutíferas comercializadas nos SAF. 
Apesar de os SAF de Tomé-Açu estarem sujeitos a mudanças ao longo do tempo, devido às condições de mercado, incidência de pragas, doenças e mudanças nas políticas públicas de beneficiamento (BARROS et al., 2009), preocupa a ideia de reduzir a diversidade de espécies. Considerando-se que a diversificação é a principal característica dos SAF locais, a Camta tem reforçado as orientações a respeito dos benefícios da diversificação, no intuito de que os sistemas consolidados não se tornem meramente consórcios agrícolas.

A respeito da intenção de explorar a madeira dos sistemas foi argumentado por parte dos agricultores empresariais (09) e somente por 01 agricultor familiar que o potencial madeireiro dos SAF merece ser mais bem aproveitado, visto que muitas árvores apresentam diâmetro para o corte. Portanto, há percepção de que a comercialização da madeira seria mais uma opção de renda para as famílias.

Apesar do interesse na exploração da madeira, os agricultores demonstraram forte preocupação com as questões legais e silviculturais que envolvem o processo. Barros et al. (2009) destacam que o plantio de espécies arbóreas madeireiras esbarra na sua derrubada, uma vez que são encontradas em diversos consórcios envolvendo fruteiras perenes. Portanto, os modelos agroflorestais em que nos arranjos não foi contemplada a extração das árvores não irão gerar renda com este componente.

Esses resultados ratificam a visão mercadológica dos agricultores empresariais, porém, não demonstram que eles sejam indiferentes às questões ambientais, pois tanto os agricultores familiares quanto os empresariais afirmaram que a sustentabilidade dos SAF só é possível quando a produção ocorre sem prejudicar o meio ambiente.

\subsubsection{SERVIÇOS ECOSSISTÊMICOS}

Em se tratando dos agricultores familiares, as árvores foram plantadas com os objetivos de sombrear as espécies frutíferas, promover os serviços ambientais e recompor a mata ciliar. Para os agricultores empresariais, os objetivos foram o sombreamento, a exploração da madeira e a coleta de produtos não madeireiros.

Quando indagados sobre a contribuição dos sistemas para a melhoria do meio ambiente, ambos os grupos relataram melhorias em relação à qualidade do ar, das plantas, o retorno da fauna, o conforto ambiental, entre outras. Os agricultores informaram que muitos animais, especialmente os pássaros, estão retornando às áreas e isso contribui para a qualidade ambiental e o bem-estar das famílias.

\footnotetext{
A concepção era de matar os animais e hoje é preciso preservar para que a harmonia seja possível. O homem se sente poderoso quando consegue matar. Com o SAF estamos conseguindo melhorar o solo, o ar, os alimentos e trazer os animais de volta (SAF-AF: 55 anos, ensino fundamental, APPRAFAMTA, presidente).

É possível produzir agredindo menos o meio ambiente. Quando meu pai plantava só pimenta-do-reino, o ambiente era muito diferente de hoje, a qualidade ambiental é melhor com o SAF (SAF-AE: 35 anos, ensino fundamental, CAMTA, sócio).
}

Nessa lógica, os SAF possibilitam ganhos econômicos e preservacionistas, uma vez que oportunizam o uso dos recursos naturais aliado à produção econômica. Para Paludo e Costabeber (2012), os agricultores conseguem manejar os componentes para aproveitar as vantagens dos serviços e produtos do sistema, rompendo o processo de "degradação", proporcionando segurança alimentar, vantagem econômica e conservação ambiental.

Nesse sentido, observa-se, em grande medida, a valorização dos agricultores familiares pelos serviços ambientais proporcionados pelo componente arbóreo, considerados superiores aos ganhos econômicos obtidos com a venda das árvores.

Ademais, as experiências empíricas e a troca de saberes têm contribuído para a mudança para uma agricultura mais sustentável, proporcionando aos agricultores transitar nas dimensões agroecológicas do processo. Em muitos SAF de Tomé-Açu foram observados a diminuição de agroquímicos e o aumento do uso de produtos naturais (compostagem e caldas orgânicas) na adubação e fitossanidade das plantas, o que demonstra a intenção de proporcionar um caráter mais sustentável aos sistemas. 


\subsubsection{ACESSO À ESCOLARIDADE E INFORMAÇÃO}

No que diz respeito à escolarização, os resultados apontaram que os agricultores familiares e empresariais apresentam bom nível de escolaridade refletido pela maior frequência de agricultores nos níveis de ensino fundamental e médio. O nível de escolaridade dos agricultores empresariais foi superior ao dos agricultores familiares, à exceção do ensino fundamental.

Nesse sentido, a escolaridade não se tornou uma barreira para a adoção dos SAF, visto que os sistemas foram implantados por agricultores de todos os níveis de escolaridade. No entanto, a superação de déficits educacionais associada à disponibilidade de cursos direcionados à área agrícola poderia aumentar a percepção positiva dos agricultores em relação aos sistemas agroflorestais.

Por fim, perguntaram-se aos agricultores quais incentivos seriam necessários para aumentar o plantio agroflorestal. Os agricultores familiares citaram a necessidade de maiores investimentos na produção de sementes e mudas, especialmente das espécies florestais, e a promoção da educação agroflorestal como enfoques que necessitam ser mais bem discutidos.

Os agricultores empresariais citaram a necessidade de ampliar a difusão dos benefícios gerados pelos SAF e a valorização do preço dos produtos como forma de atrair os agricultores para o plantio agroflorestal. Precisa ter mais investimento para a produção de mudas e comprar insumos" (SAF-AF: 50 anos, Ensino fundamental, Aprafamta, sócio); "Também acho que deveria ter mais informação e educação sobre os sistemas agroflorestais". (SAF-AF: 42 anos, ensino médio, Apprafamta, sócio); "Devem ser mostradas as vantagens dos custos e dos benefícios que os SAF geram" (SAF-AE: 42 anos, ensino médio, Camta, sócio).

Para Franzel et al. (2004), o acesso à informação de fato é um aspecto importante e está diretamente relacionado com o nível de escolaridade dos agricultores. Além disso, a obtenção de recursos para o estabelecimento e manejo dos sistemas também pode ser determinante para a sua adoção.

Apesar desses resultados, Rosa et al. (2009); Pompeu et al. (2012); Vieira et al. (2013) e Ferreira et al. (2014) esclarecem que o nível de escolaridade não é um fator determinante para a adoção dos SAF. Questões de gênero, a organização social e características socioculturais e econômicas também são importantes na sensibilização dos agricultores.

Assim, as observações sobre percepção ambiental aqui discutida permitiram constatar que alguns pontos trazem luzes para a compreensão da relação homem-natureza no manejo dos sistemas. Entretanto, os resultados não permitiram esclarecer de que modo as distintas percepções têm influenciado a capacidade produtiva dos sistemas locais.

A possibilidade de incorporar às pesquisas futuras a potencialidade dos SAF de Tomé-Açu a partir das percepções construídas, poderá fornecer resultados a fim de compreender melhor a sustentabilidade dos sistemas considerando a percepção dos agricultores agroflorestais.

\section{CONSIDERAÇÕES FINAIS}

Os agricultores familiares e empresariais de Tomé-Açu possuem percepções distintas sobre os sistemas agroflorestais. A produção agroflorestal familiar e empresarial baseia-se em uma produção econômica com viés ambiental que influencia a percepção dos agricultores.

O aspecto ambiental é fortemente considerado pelos agricultores familiares especialmente devido à sua visão histórico-cultural de manejo dos sistemas, à necessidade de sombreamento das árvores para as espécies frutíferas e à percepção de valorizar os serviços ecossistêmicos proporcionados pelos SAF.

O apoio gerencial da Camta proporciona aos agricultores empresariais maior segurança na implantação e manejo dos SAF, enquanto que a Apprafamta auxilia coletivamente os agricultores familiares na resolução de problemas e no incentivo à produção sustentável. Ademais, o apoio das instituições de ensino e pesquisa presentes em Tomé-Açu é importante na difusão da informação e do intercâmbio de experiências para a transição agroecológica. 
Assim, torna-se necessária maior valorização dos sistemas agroflorestais a fim de sensibilizar um número cada vez crescente de agricultores a iniciar o processo de transição. As políticas públicas são fundamentais nesse processo fornecendo suporte para que as famílias no rural possam desenvolver a atividade agroflorestal e fortalecer o caráter sustentável da produção agrícola.

\section{REFERÊNCIAS}

ABDO, M. T. V. N.; VALERI, S. V.; MARTINS, A. L. M. Sistemas agroflorestais e agricultura familiar: uma parceria interessante. Revista Tecnologia \& Inovação Agropecuária, São Paulo, v. 1, n. 2, p. 50-59, dez. 2008.

ALENCAR, E.; GOMES, M. A. O. Ecoturismo e planejamento social. Lavras: UFLA/FAEPE, 2001. 103 p.

ARCE, A.; LONG, N. (Ed.). Anthropology, development and modernities: exploring discourses, countertendencies and violence. London : Routledge, 2000. 232 p.

BARROS, A. V. L. et al. Evolução e percepção dos sistemas agroflorestais desenvolvidos pelos agricultores nipo-brasileiros do município de Tomé-Açu, estado do Pará. Amazônia: Ciência \& Desenvolvimento, Belém, v. 5, n. 9, p. 07-37, jul.-dez. 2009.

BOLFE, E. L.; BATISTELLA, M. Análise florística e estrutural de sistemas silviagrícolas em Tomé-Açu, Pará. Pesquisa agropecuária brasileira, Brasília, v. 46, n. 10, p. 1139-1147, out. 2011.

BRASIL. Lei n. 11.326, de 24 de julho de 2006. Estabelece as diretrizes para a formulação da Política Nacional da Agricultura Familiar e Empreendimentos Familiares Rurais. Diário Oficial [da] República Federativa do Brasil, Brasília, DF, 25 jul. 2006. Disponível em: <http://www2.camara.leg.br/legin/fed/ lei/2006/lei-11326>. Acesso em: 18 mar. 2009.

BÜHLER, E. A.; OLIVEIRA, V. L. Agricultura empresarial: novidades e desafios para a pesquisa sobre o rural. In: XXI ENCONTRO NACIONAL DE GEOGRAFIA AGRÁRIA. TERRITÓRIOS EM DISPUTA: OS DESAFIOS DA GEOGRAFIA AGRÁRIA NAS CONTRADIÇÕES DO DESENVOLVIMENTO BRASILEIRO. Uberlândia, MG, 15 a 19 de outubro de 2012.

CASTRO, A. P. C. et al. Os sistemas agroflorestais como alternativa de sustentabilidade em ecossistemas de várzea no Amazonas. Acta amazônica. v. 39, n. 2, p. 279-288, 2009.

CAUME, D. J. Agricultura Familiar e Agronegócio: falsas antinomias. Redes. Santa Cruz do Sul, v. 14, n. 1, p. 26-44, jan.-abr. 2009.

DEL RIO, V.; OLIVEIRA, L. Percepção ambiental: a experiência brasileira. 2. ed. São Paulo: Studio Nobel, 1999.

DUBOIS, J. C. L.; VIANA, V. M. Manual Agroflorestal para a Amazônia. Rio de Janeiro, REBRAF / Fundação Ford, 2. ed. 1998, $228 \mathrm{p}$.

EMBRAPA. Centro de Pesquisa Agroflorestal da Amazônia Ocidental. Manaus. Programa Nacional de Pesquisa Agroflorestal. 1991. 39 p.

FARREL, J. G.; ALTIERI, M. A. Sistemas agroflorestais. In: Agroecologia: bases científicas para uma agricultura sustentável. 3. ed. São Paulo, Rio de Janeiro: Expressão Popular, AS-PTA. 2012, p. 282-304.

FERNANDES, V. M. A. Manejo de árvores em sistemas agroflorestais cacaueiros: percepção dos agricultores do sul da Bahia, Brasil. 2008. 108p. Dissertação (Mestrado em Agroecossistemas) Universidade Federal de Santa Catarina, Florianópolis, 2008.

FERREIRA, D. C. F.; POMPEU, G. S. S.; FONSECA, J. R. C. Sistemas agroflorestais comerciais em áreas de agricultores familiares no município de Altamira, Pará. Revista Brasileira de Agroecologia, Porto Alegre, v. 9, n. 3, p. 104-116, jul.-set. 2014. 
FLICK, U. Desenho da pesquisa qualitativa. Tradução de Roberto Cataldo Costa. Porto Alegre, Artmed, 2009. $164 \mathrm{p}$.

FRANZEL, S. et al. Methodos for assessing agroflorestry adoption potential. In: FRANZEL, S.; SCHERR, S. J. (Ed.). Trees on the farms: assessing the potential of agroflorestry practices in África. Nirobi: CAB/ ICRAF. 2004. 197 p.

FRAXE, T. J. P. et al. Natureza e Mundo Vivido: o espaço e o lugar na percepção da família cabocla/ ribeirinha. In: SCHERER, E.; OLIVEIRA, J. A. (Org.). Amazônia: políticas públicas e diversidade cultural. Rio de Janeiro: Garamond. 2006, 260 p.

GERHARDT, T. E.; SILVEIRA, D. T. Métodos de pesquisa. Universidade Aberta do Brasil - UAB/UFRGS, Curso de Graduação Tecnológica - Planejamento e Gestão para o Desenvolvimento Rural da SEAD/ UFRGS. - Porto Alegre: Editora da UFRGS, 2009.

GLIESSMAN, S. R. et al. Agroecología: promoviendo una transición hacia la sostenibilidad. Revista Ecossistemas, [s.I], v. 16, n. 1, p. 13-23, jan.-abr. 2007.

GONZÁLEZ, I. O. Conocimiento local y decisiones de los productores de Alto Beni, Bolivia, sobre el diseño y manejo de la sombra en sus cacaotales. 2006. 76p. Dissertação (Mestrado el desarrollo y la conservación) - Centro Agronómico Tropical de Investigación y Enseñanza. Turrialba, 2006.

GOULART, I. C. G. et al. Fatores relacionados à adoção de práticas de manejo em sistemas agroflorestais sucessionais na região norte de Mato Grosso. Rev. Bras. de Agroecologia, v.11, n. 3, p. 196-205, 2016.

HOMMA, A. Imigração japonesa na Amazônia: sua contribuição para o desenvolvimento agrícola. Belém: Embrapa Amazônia Oriental, 2007.

INSTITUTO BRASILEIRO DE GEOGRAFIA E ESTATÍSTICA. Estatísticas municipais. Disponível em <http:// www.cidades.ibge.gov.br/xtras/home.php>. Acesso em: 12 fev. 2016.

KATO, O.; TAKAMATSU, J. Tomé-Açu. In: Iniciativas promissoras e fatores limitantes para o desenvolvimento de sistemas agroflorestais como alternativa à degradação ambiental na Amazônia. Anais... Belém /Tomé-Açu, Pará, 2005. p. 12.

LEFÈBVRE H. La production de l'espace. Paris: Anthropos, 4a ed., 2000.

MARIN, A. P.; OLIVEIRA, H. T.; COMAR, V. A educação ambiental num contexto de complexidade do campo teórico da percepção. Interciência, Caracas, v. 28, n. 10, p. 616-619, out. 2003.

MARIN, A. A. Pesquisa em educação ambiental e percepção ambiental. Pesquisa em Educação Ambiental, São Paulo, v. 3, n. 1, p. 203-222, jan.-jun. 2008.

MAY, P. H. Manual Agroflorestal para a Mata Atlântica. DEITENBACH, A. et al. (Org.). Brasília: Ministério do Desenvolvimento Agrário, Secretaria de Agricultura Familiar, 2008. 196 p.

NAIR, P. K. R. Soil productivity Aspects of agroforestry. Nairobi: ICRAF, 1984.

PACHÊCO, N. A.; BASTOS, T. X. Boletim agrometeorológico 2005 - Tomé-Açu. Belém: Embrapa Amazônia Oriental, 2008. 35 p. Embrapa Amazônia Oriental Documentos 277.

PALUDO, R.; COSTABEBER, J. A. Sistemas agroflorestais como estratégia de desenvolvimento rural em diferentes biomas brasileiros. Revista Brasileira de Agroecologia. Porto Alegre, v. 7, n. 2, p. 63-76, ago. 2012.

PEZARICO, C. R. et al. Indicadores de qualidade do solo em sistemas agroflorestais. Rev. Ciênc. Agrár., v. 56, n. 1, p. 40-47, jan.-mar. 2013. 
PINHEIRO, S. L. G. O enfoque sistêmico e o desenvolvimento rural sustentável: uma oportunidade de mudança da abordagem hard-systems para experiências com soft-system. Agroecologia e Desenvolvimento Sustentável. Porto Alegre, v. 1, n. 2, abr./jun.2000, p. 27-37.

POMPEU, G. S. S.; ROSA, L. S.; VIEIRA, T. A. Adoption of agroforestry systems by smallholders in brazilian amazon. Tropical and Subtropical Agroecosystems, Yucatán, v. 15, n. 1, p. 165-172, jan.-abr. 2012.

PORRO, R. (Org.). Alternativa agroflorestal na Amazônia em transformação. Brasília: Embrapa/Icraf, 2009. p. 645-670.

RAIOL, C. S.; ROSA, L. S. Sistemas Agroflorestais na Amazônia Oriental: o caso dos agricultores familiares de Santa Maria do Pará, Brasil. Rev. Bras. Ciênc. Agrár. v. 8, n. 2, p. 258-265, 2013.

RIBASKI, J.; MONTOYA, L. J.; RODIGHERI, H. R. Sistemas Agroflorestais: aspectos ambientais e socioeconômicos. Informe Agropecuário, Belo Horizonte, v. 22, n. 212 p. 61-67, set.-out. 2001.

RICHARDSON, R. J. Pesquisa social: métodos e técnicas. São Paulo: Atlas, 1989.

RODRIGUES, T. E. et al. Zoneamento agroecológico do município de Tomé-Açu, Estado do Pará. Belém: Embrapa Amazônia Oriental, 2001. 81 p. Embrapa Amazônia Oriental Documentos n. 118.

ROSA, L. S. et al. Limites e oportunidades para a adoção de sistemas agroflorestais pelos agricultores familiares da microrregião de Bragantina, PA. In: PORRO, R. (Org.). Alternativa agroflorestal na Amazônia em transformação. Brasília: Embrapa/Icraf, 2009. p. 645-670.

SOUZA, P. M. et al. Agricultura Familiar Versus Agricultura Não Familiar: uma análise das diferenças nos financiamentos concedidos no período de 1999 a 2009. Documentos técnicos científicos. v. 42, n. 01, p. 106-124, Jan.-Mar. 2011.

SPSS-Statistical Package for the Social Sciences. Version 19.0 [S.I]: Software livre. New York, 2009. Disponível em: <http://www-01.ibm.com/software/br/analytics/spss>. Acesso em: 08 out. 2016.

TAFNER JÚNIOR, A. W.; SILVA, F. C. Colonização nipônica na Amazônia: a saga dos imigrantes japoneses no estado do Pará. Revista Pós-Ciências Sociais. São Luiz, v. 11, n. 22, p. 239-260, jul.-dez. 2014.

UMRANI, R.; JAIN, C. K. Agroforestry Systems and Practices. Jaipur: Oxford Book Company, 2010.

VIEIRA, T. A.; ROSA, L. dos S.; SANTOS, M. M. de. L. S. Condições socioeconômicas para o manejo de quintais agroflorestais em Bonito, Pará. Rev. Bras. Ciênc. Agrár. v. 8, n. 3, p. 458-463, 2013.

VILLAR, L. M. et al. A percepção ambiental entre os habitantes da região noroeste do estado do Rio de Janeiro. Esc. Anna Nery Ver. Enferm., v. 12, n. 3, p. 537-43, set. 2008.

YAMADA, M. Uma breve história de desenvolvimento agroflorestal Nikkei na Amazônia: o caso da colônia de Tomé-Açu, PA. In: PORRO, R. Alternativa agroflorestal na Amazônia em transformação. Brasília: Embrapa Informação Tecnológica, 2009. p. 691-704. 